\title{
Repair of local damages to precast prestressed slab elements at a parking garage
}

\author{
Marta Lutomirska ${ }^{1 *}$, Tomasz Lutomirski ${ }^{2}$, and Artur Sakowski ${ }^{3}$ \\ ${ }^{1}$ Warsaw University of Technology, 00-661 Warsaw, Poland \\ ${ }^{2}$ Gaz-System S.A., 02-337 Warsaw, Poland \\ ${ }^{3}$ Road and Bridge Research Institute, 03-302 Warsaw, Poland
}

\begin{abstract}
The durability of precast structures often depends on quality of execution of the connections between the structural elements. Essential also is their design and proper exploitation. This paper focuses on the magnitude of damages as well as repair methods used for a precast slab, which consists of prestressed double $\mathrm{T}$ slab elements supported on prestressed inverted $\mathrm{T}$ girders. It was found that during execution, the girders were forced to fit dowel bars, which resulted in their initial deformation. Moreover, those connection zones were subjected to unpredicted loading coming from delivery trucks. It resulted in crushing of the elastomeric bearings, uncontrolled rotation of double $\mathrm{T}$ precast elements, and further deformation of dowel bars. Numerous cracks, splits, concrete spalling, surface rust stains, and efflorescence were observed. To prevent failure, a project for repair was developed. The slab was lifted with the use of a jacks to provide necessary space for work. Damaged dowel bars and elastomeric bearings were removed. The concrete surface of double $\mathrm{T}$ beams and the inverted $\mathrm{T}$ girder was cleaned, refilled, prepared, and strengthened with FRP wraps. Additionally, steel angles were used to protect the edges of the inverted $\mathrm{T}$ girder.
\end{abstract}

\section{Introduction}

Structural precast elements are characterized with very high quality owing to high quality control during the production process, which can be more easily obtained in factories than on construction sites. The precast concrete industry uses concrete mixes that cure fast, achieve high early compressive strengths, provide low permeability, and guarantee durability. However, the durability of precast structures is also sensitive to the quality of assembly and proper exploitation of the structure. In particular, potential risk zones are the connections of precast elements. influencing structural integrity. Over the years, precast producers have developed a variety of connection details to fulfil design code requirements and provide optimal solutions. Despite this fact, they tend to provoke problems of complex origins [1-3]. The mistakes leading to structural failure may arise at the stage of design, construction, and exploitation [4].

\footnotetext{
*Corresponding author: m.lutomirska@il.pw.edu.pl
} 
The aim of this paper is to present and discuss the magnitude of damages as well as repair methods for a precast slab in a parking garage of a shopping centre. Numerous structural defects that raised concern were located at the connection zone of prestressed elements. The assessment of the condition of the structure led to necessity of urgent repair.

\section{Description of the precast slab}

The assessment object was a precast slab structure, which consisted of prestressed double tee slab elements supported on prestressed inverted T girders, which transfer loads to columns and foundation pads. The double tee slab elements were $80 \mathrm{~cm}$ high and $248 \mathrm{~cm}$ wide. Their span was $16 \mathrm{~m}$, and they were spaced every $250 \mathrm{~cm}$, which resulted in designed $4 \mathrm{~cm}$ gaps between the elements. Their ends were notched in order to decrease the slab height. The height of the inverted $\mathrm{T}$ girders supporting the slab elements was also equal to $80 \mathrm{~cm}$. The effect of a monolithic slab structure was obtained by filling the gaps between the double tee elements and adding a cast-in-place reinforced concrete slab of $14 \mathrm{~cm}$ at the top of the precast elements. The slab was divided by expansion joints into fields $33.0 \times 22.5 \mathrm{~m}$. The finishing of the slab was a cobblestone pavement. The connections between double tee elements and the inverted $\mathrm{T}$ girders were designed as simple supports on one side and pinned supports on the other side. In the simple supports sliding elastomeric bearings 250x200x10 mm were used, while in the pinned supports, sliding elastomeric bearings and dowel bars were applied. The dowel bars of diameter equal to $20 \mathrm{~mm}$ were fit to the sleeves of diameter equal to 50 mm.

This paper focuses on a part of the structure located between axes $G$ and $H$, where the observed damages occurred. The elements of concern were one $\mathrm{T}$ girder and four double $\mathrm{T}$ slab elements. In figure 1, a schema showing elements of the precast slab was presented.

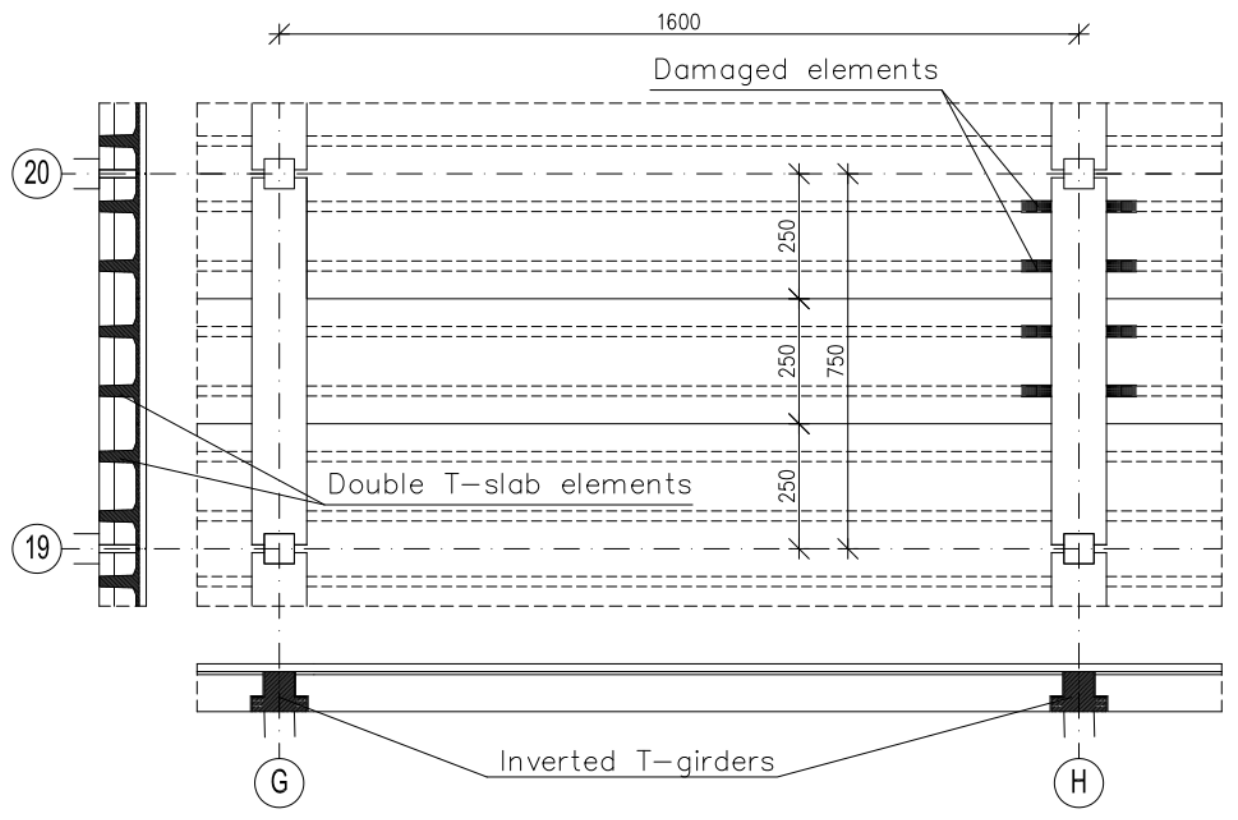

Fig. 1. Layout of the precast slab. 


\section{Assessment of damages to the structure}

During exploitation of the structure, damages occurred to the double T-slab elements and the inverted $\mathrm{T}$ girder. The effected zone was mostly the connection at the pinned support (axis $\mathrm{H}$ ). The damages to double tee slab elements were the following: the diagonal cracks of $0.3 \mathrm{~mm}$ width inclined 30 to $50^{\circ}$ in the notch zone (figures $2 \mathrm{a}, 2 \mathrm{~b}$ ), cracks, splits and concrete spalling (figures $2 \mathrm{a}, 2 \mathrm{~b}, 2 \mathrm{c}$ ), surface rust stain and efflorescence (figures $2 \mathrm{e}$ ). The damages to inverted $\mathrm{T}$ girders were the following: splits and concrete spalling (figures $2 \mathrm{~b}$, $2 \mathrm{c}$ ), and surface rust stain (figures $2 \mathrm{a}, 2 \mathrm{~d}$ ). At the pinned support the elastomeric bearings were crushed. It was observed that the splitting of the concrete often crosses the centre of elastomeric bearings (figure 2c). In the mid span of the double tee elements transverse cracks with efflorescence were found (figure 2e). Many of the expansion joints were exceeding the designed value of $25 \mathrm{~mm}$. One of the expansion joints was $66 \mathrm{~mm}$ wide and it was blocked by a wooden scantling (figure $2 \mathrm{f}$ ).

a)

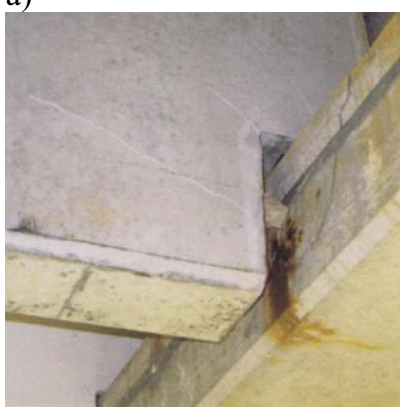

d)

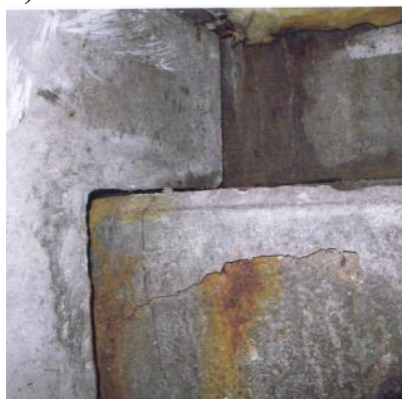

b)

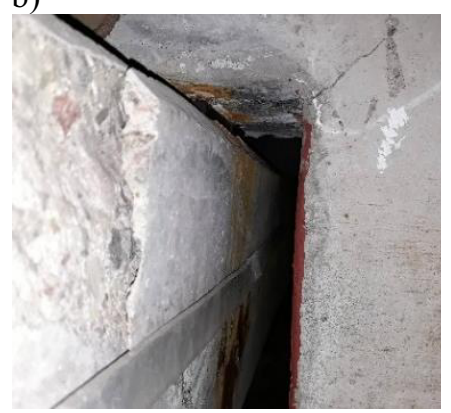

e)

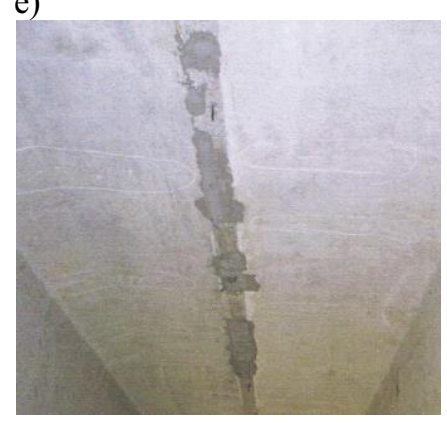

c)

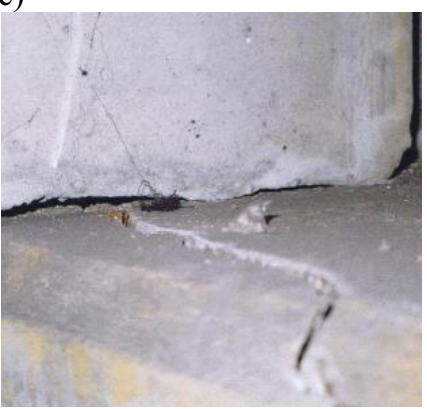

f)

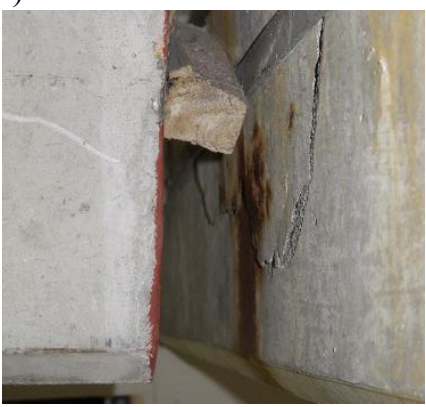

Fig. 2. Damages to the double $\mathrm{T}$ slab elements and the inverted $\mathrm{T}$ girder.

If was found that the assessed precast slab was subjected to excessive loading from the top. During renovation of the pavement a layer of subbase and cobblestone was added, which was not considered in the design. Moreover, the loading zone for delivery trucks was located unfortunately directly above the connection of the precast elements. This type of loading was not taken into consideration during the design. The characteristic value of variable load assumed in the calculations was equal to $3.90 \mathrm{kN} / \mathrm{m}^{2}$, while the value of the extreme load was $15 \mathrm{kN} / \mathrm{m}^{2}$, which was based on the weight of a fire engine. Overloading resulted in crushing of the elastomeric bearings. The double $\mathrm{T}$ slab elements became directly supported on the inverted $\mathrm{T}$ girder, which provoked uncontrolled rotation of double $\mathrm{T}$ precast elements, deformation of the dowel bars, and additional force on the edge of the inverted $\mathrm{T}$ girders. Concrete splitting and spalling were obvious consequences of crushed elastomeric bearings. The splitting of the concrete was crossing the centres of the elastomeric bearings and they 
were going in the vicinity of the dowel bars and sleeves. The cracks observed in the midspan of the double $\mathrm{T}$ slab elements were characteristic for overloaded elements. Their direction was perpendicular to the direction of tensile stresses. At the supports, the diagonal cracks resulted from shear forces, since the value of the bending moment is small. Beyond overloading of the structure, some errors that occurred during assembly of the precast elements were identified. The executed dilatation gaps were much wider than those designed. It was concluded that the girders were forced to fit dowel bars, which resulted in their initial deformation.

Numerous cracks, concrete splitting and spalling, progressed corrosion visible in the form of surface rust stain and white efflorescence in the crack zones raised alert and concern about the safety of the structure. It was stated that the precast elements were at risk of failure and urgent repair was necessary.

\section{Methods of repair}

Due to the critical state of the structure, the repair works started immediately. The goal of the works was to solve the problem of cracks and splits in the concrete and crushed elastomeric bearings. The damaged part of the structures was put out of service. The double $\mathrm{T}$ elements were temporary supported on both sides, at the distance of $50 \mathrm{~cm}$ from the axes of previous supports. The slab was lifted with the use of a jack to provide necessary space for work including strengthening of the double $\mathrm{T}$ beams, protecting the inverted $\mathrm{T}$ girder and changing of the elastomeric bearings. It was a challenging task, because of the composite action between the precast elements and the reinforced concrete slab. The pavement was removed to observe the cracks at the top of the slab. In order to avoid damage to the continuous slab, also the spans adjacent to the damaged ones were lifted. It was necessary to select the adequate number of jacks, the value of force, and the places of support (figure 3). During the unloading process the vertical displacement of the pre-cast members as well as the supporting girder were monitored with the use of analogue gauges. The space of $11 \mathrm{~mm}$ was reached without damage to the composite slab. It was possible owing to the special gasket placed between the prefabricated elements and the cast-in-place slab at the stage of construction. In figure 4 , photos from the lifting of the slab are presented.

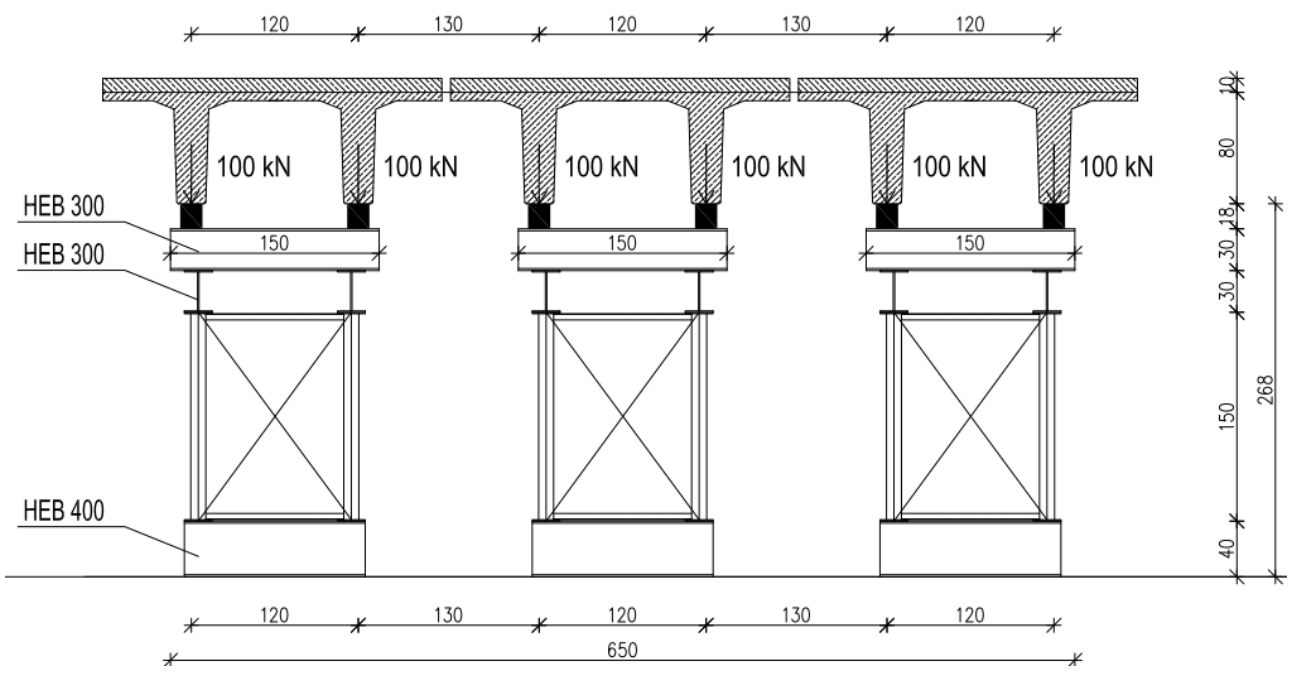

Fig. 3. Schema for the heavy lifting of the precast slab. 

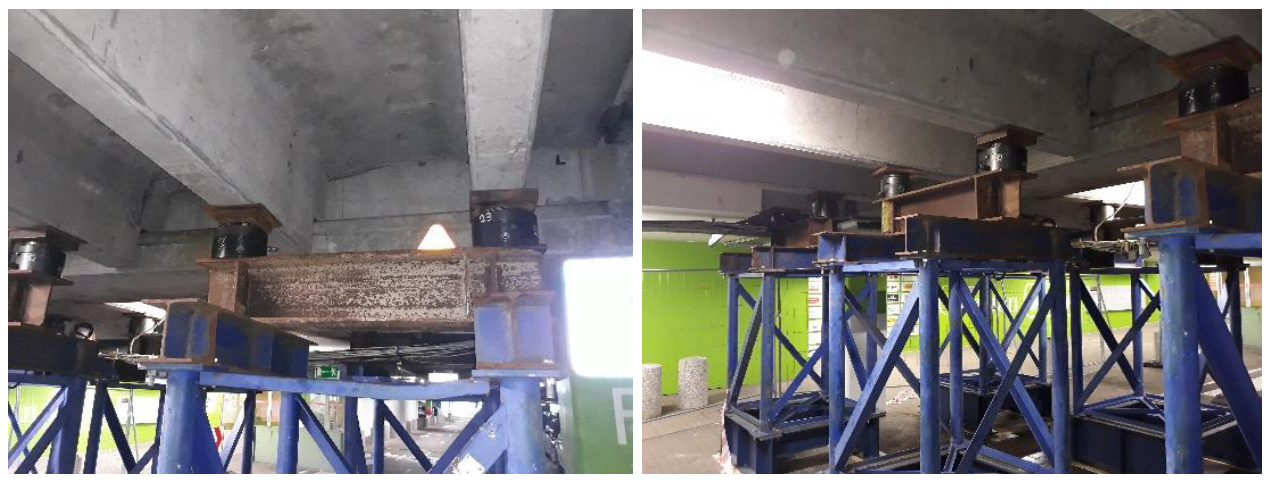

Fig. 4. Heavy lifting of the precast slab.

The process of unloading of the structure facilitated further evaluation of damages. The wooden scantlings and undesired utilities were removed. At the zones of connection of the precast elements, the structure was cleaned from the spalled concrete and mortar in order to fully evaluate all damages. The final version of the project for repair could be elaborated. It included strengthening of double $\mathrm{T}$ beams with FRP wraps (figure 5) and protecting the inverted $\mathrm{T}$ girder with steel angles (figure 6). Strengthening with FRP wraps became a recognized solution for strengthening of reinforced concrete and other types of structures [57]. However, since FRP wraps application in strengthening is a comparatively new solution, the design specifications regarding them still undergo development. There are several available design specifications, for example [8-10].
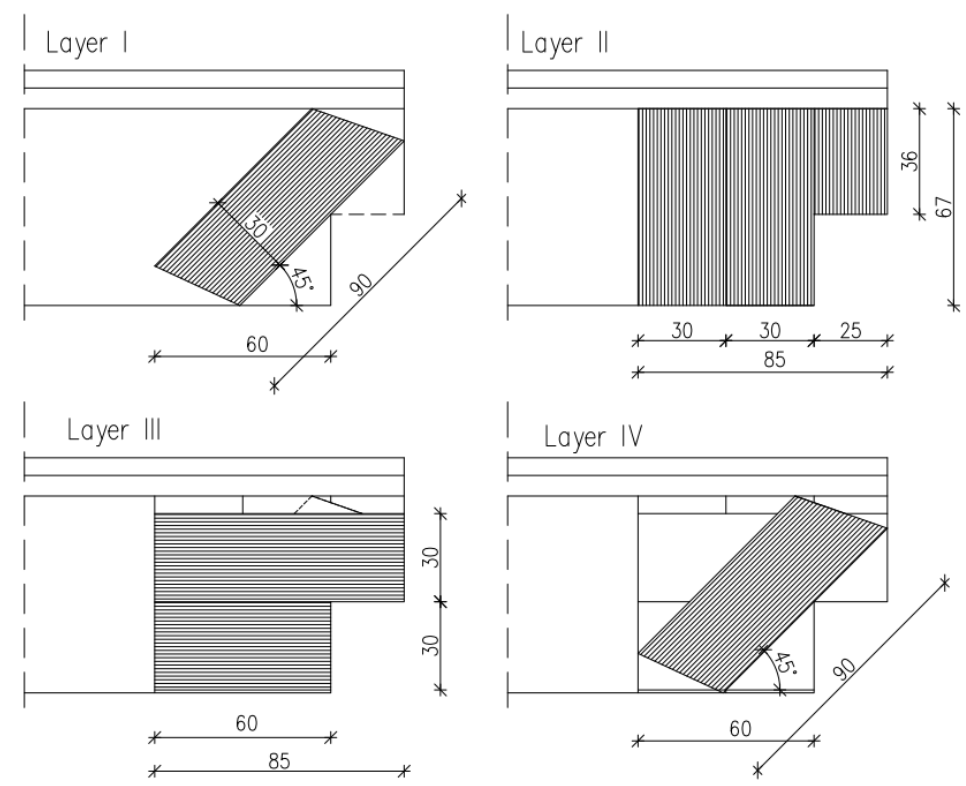

Fig. 5. The orientation of the consecutive layers of FRP wraps. 


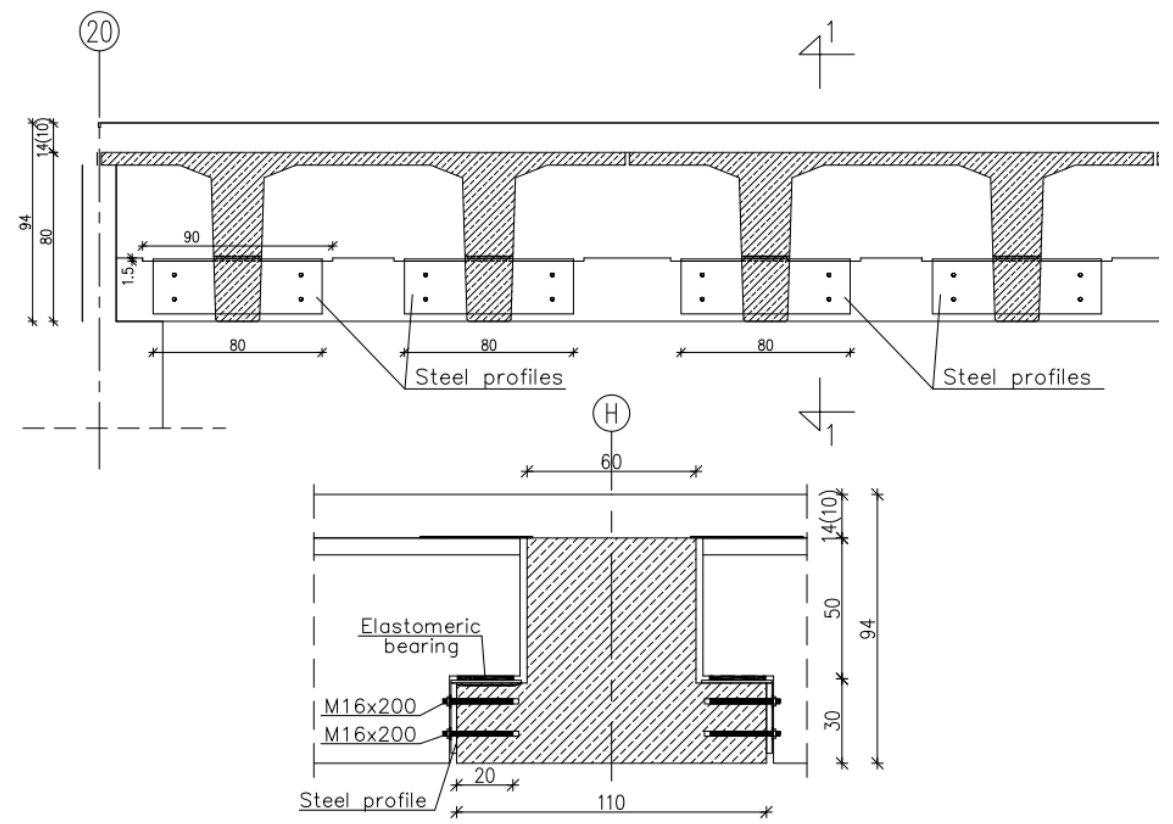

Fig. 6. Protecting of the inverted $\mathrm{T}$ girder with a steel angle.

The repair of the structure was started with surface sanding to clean the concrete surface of double $\mathrm{T}$ beams and the inverted T girder. Then they were refilled with the PCC mortar. After the curing time of the PCC mortar, the precast girder surfaces were primed for strengthening with aramid FRP wraps in the area with the distance $1.2 \mathrm{~m}$ from the support axis. The four layers in the different orientations of FRP wraps (each $0.166 \mathrm{~mm}$ ) were applied according to the design. They were intended to cover the webs from both sides and envelope them from the bottom (figures 7a). The wet lay-up process with the use of resin was applied. The manufacture restriction was that the next layer must be applied within the 60 minutes (wet to wet). Otherwise, if this time limit was exceeded, it was required to wait at least 12 hours for curing, before starting application of the next layer of FRP wrap. As well, along the bottom flange of the inverted $\mathrm{T}$ girder,FRP laminates were applied (figure $7 \mathrm{~b}$ ). Unloading and lifting of the slab, resulted in change of internal forces in the structure and closure of transverse cracks.

The inverted $\mathrm{T}$ girder was trimmed $15 \mathrm{~mm}$ at the zones of support of the double $\mathrm{T}$ beams. It was noticed that the dowel bars needed to connect the precast elements were located too close to the edge of the inverted $\mathrm{T}$ girder, which caused cracks in the elements. The damaged elastomeric bearings and the dowel bars were removed (figure 8). Steel angles $\mathrm{L} 250 \times 10 \times 250 \times 20 \mathrm{~mm}$ were used for to protect edges of the inverted T girder and to provide proper support for the precast slab members (figure 9). In the steel angles the holes were prepared and injectable adhesive anchorages were used. Additionally, a resin was used to connect the steel profiles to the concrete surface. Once the full compressive strength of the resin was reached, in the gaps between the steel plates and the precast girder new reinforced elastomeric bearings were placed (figure 10). The elastomeric bearings were designed individually to fit the remaining space. When the curing time of the FRP materials was reached, the structure was slowly lowered to its original position. All temporary supports were removed, and the structure was returned to service. 
a)

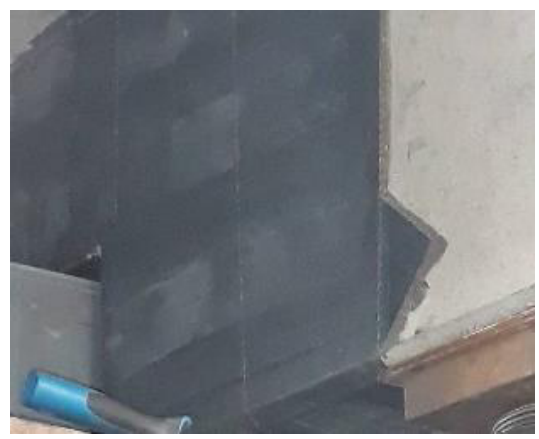

b)

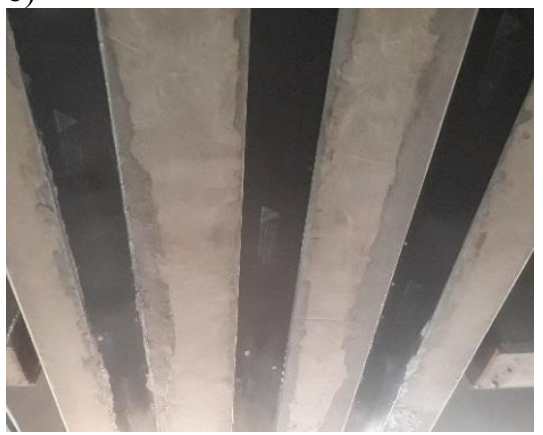

Fig. 7. Strengthening with FRP wraps.
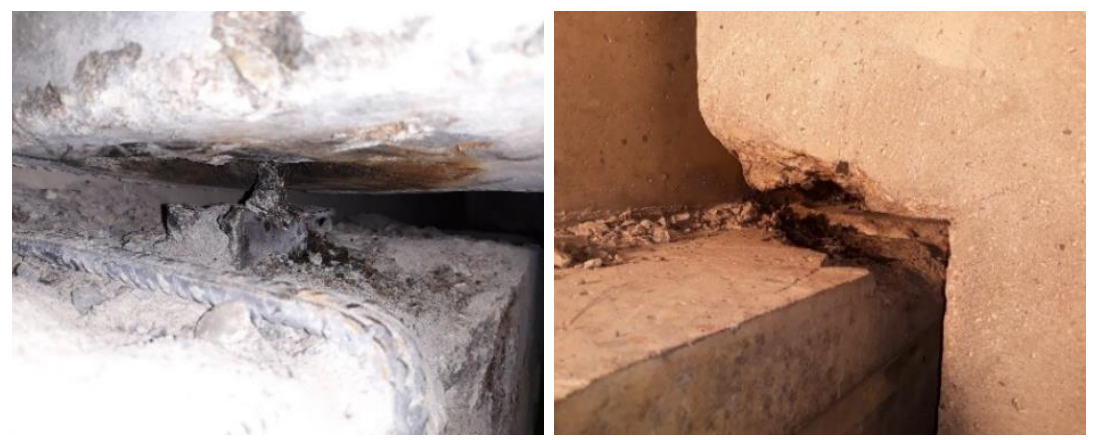

Fig. 8. Removing of the elastomeric bearings and the dowel bars.
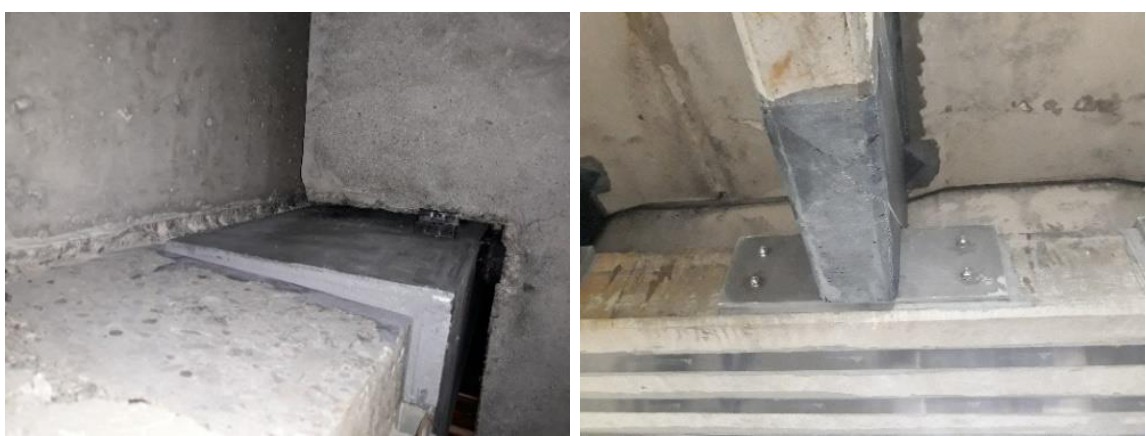

Fig. 9. Application of a steel angle for the inverted $\mathrm{T}$ girder.

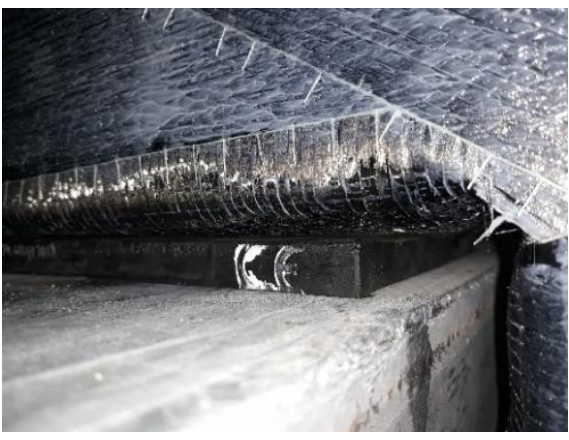

Fig. 10. New elastomeric bearing. 


\section{Summary and conclusions}

The objective of this paper was to present and discuss the assessment of damages occurred to the precast slab in a parking garage, as well as the process of repair. The damages to the prestressed double $\mathrm{T}$ slab elements and the prestressed inverted T girder supporting them had the form of cracks, splits, concrete spalling, surface rust stains, and efflorescence. They resulted from unplanned loading at the top of the slab, and some inaccuracies during construction. The structure was classified as undergoing risk of failure. The repair required lifting of the structure, removal of damaged concrete and elastomeric pads, application of FRP wraps, steel angles, and injectable adhesive anchorages.

In the precast structures, a special concern should be paid the connections between elements. They are zones of potential risk and may influence structural integrity. It was concluded that the durability of the structure can be affected at the stage of design, construction, and exploitation. In case of the analysed precast slab the following errors occurred, at the stage of design - not considering all possible loading on the structure, at the stage of construction - imprecise assembly of the elements, and at the stage of exploitation overloading of the structure. The numerous damages occurred to the structure as chain reaction.

\section{References}

1. A. de la Fuente, J.M. Bairán, S.H.P. Cavalaro, Case study of failure of long prestressed precast concrete girder during lifting, Eng Failure Analysis 100, pp. 512-519, (2019)

2. D. Kaminetzky, Design and Construction Failures. Lessons from Forensic Investigations, McGraw-Hill, New York, USA (1991)

3. M. Moravcik|. P. Bujnakova, F. Bahled, Failure and damage of a first-generation precast prestressed bridge in Slovakia, Structural Concrete 21, pp. 2353-2362, (2020)

4. M. Lutomirska, Simultaneous occurrence of loads resulting in structural failures, Theoretical Foundations of Civil Engineering 5, pp. 119-128, Warsaw, Poland (2014)

5. K. Rodsin, Q. Hussain, P. Joykland, A. Nawaz, and H. Fazliani, Seismic strengthening of nonductile bridge piers using low-cost glass fiber polymers, Bulletin of the Polish Academy of Sciences, Technical Sciences 68(6), (2020)

6. M. Bakalarz, P. G. Kossakowski, Mechanical properties of laminated veneer lumber beams strengthened with CFRP sheets, Archives of Civile Engineering 65(2), (2019)

7. T. C. Triantafillou, C. P. Antonopoulos, Design of concrete flexural members strengthened in shear with FRP, J. Compos. Construct 4(4), 198-205, (2000)

8. ACI Committee 440, ACI 440.2R-02-Guide for the design and construction of externally bonded FRP systems for strengthening concrete structures, Farmington Hills, MI, USA (2002)

9. FIB-TG 9.3, Design and Use of Externally Bonded Fiber Polymer Reinforcement (FRP EBR) for Reinforced Concrete Structures, Bulletin 14, Lausanne, Swiss (2001)

10. ISIS, Design Manual 4. Strengthening Reinforced Concrete Structures with ExternallyBonded Fiber Reinforced Polymers, Intelligent Sensing for Innovative Structures, Winnipeg, Canada (2001) 